\title{
74 Physical exercise and the skeletal system
}

The major positive effects of strength and endurance training on bones and joints include:

- increase in bone mass

- increase in cartilage metabolism

- cross-sectional enlargement of the fibrils in connective tissue structures

The supporting tissue in the human body includes approximately 208 bones, the number of which can vary slightly from individual to individual. The bones make up $12-14 \%$ of the body's weight.

The most common cells in bone are osteocytes. Osteocytes are former osteoblasts that have become permanently embedded within the bone matrix after fulfilling their function of building up bone. The long-living osteocytes send out signals telling the body where and how much bone needs to be renewed by osteoclasts and osteoblasts.

The sum of all forces working on the bone dictates the degree of cellular activity in the bone. That is also how proper exercise stimuli can achieve a measurable gain in bone mass ( $\downarrow$ Chapter 77 ). However, only skeletal portions affected by muscle contraction forces respond to these stimuli. Stress stimuli must significantly exceed those of normal daily activities.

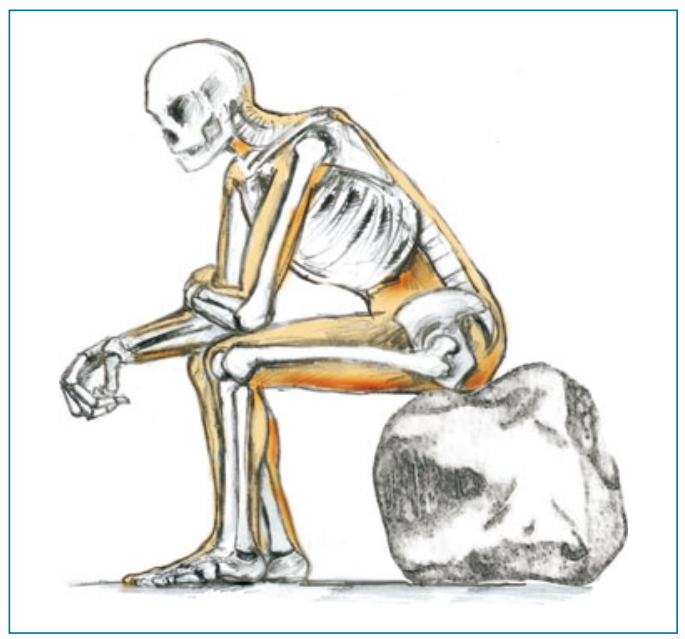

- Fig. 74.1 A skeleton taking a break

A large amount of muscle mass usually correlates with healthy bone strength.

An increase in bone mass of up to $1 \%$ per year is possible. this is identical to the natural rate of decrease in bone mass starting at about the age of 35 . 